\title{
Dicionários de Línguas Indígenas e Lexicografia Pedagógica
}

\section{Indigenous Languages Dictionaries and Pedagogical Lexicography}

Cristina Martins FARGETTI (UNESP) cmfarget@gmail.com

Juliana Nazatto MONDINI (UNESP) juliana.mondini@gmail.com

Recebido em: 01 de jul. de 2020. Aceito em: 30 de jul. de 2020.

\section{FARGETTI, Cristina Martins; \\ MONDINI, Juliana Nazatto. Dicionários de Línguas Indígenas e Lexicografia Pedagógica. Entrepalavras, Fortaleza, v. 11, n. esp., p. 19-40, 2021. DOI: 10.22168/2237-6321-10esp1972.}

\section{Resumo: Demonstramos} $\mathrm{O}$ desenvolvimento de políticas linguísticas que possibilitam ações de educação indígena a partir das línguas nativas. Refletimos sobre estudos do léxico de línguas minoritárias, como as línguas indígenas brasileiras, a relevância de pesquisas de léxico de especialidade, que contribui para obras terminográficas e lexicográficas. Levando em conta a proposta da Terminologia Etnográfica (FARGETTI, 2019), é abordado o campo da culinária entre os juruna do Território Indígena do Xingu, Mato Grosso, e como seu tratamento em vocabulário terminológico pode contribuir para a educação bilíngue intercultural e para o registro de parte importante de uma cultura tupi brasileira. Para isso, uma metodologia específica de trabalho de campo é necessária, com um diálogo entre ciências: a do pesquisador linguista e a do especialista indígena em uma área do saber. Assim, é apresentada uma discussão de verbete em juruna, com suas subentradas, elaborado por Mondini (2014), em comparação com verbete de obra lexicográfica sobre outra língua indígena brasileira, kaingang, o que permite uma contribuição aos Estudos do Léxico e sua utilização no ensino.

Palavras-chave: Dicionário de língua indígena. Educação. Terminologia Etnográfica. 


\section{v. 11 (esp.)}

19-40 ago. 2021

Abstract: We demonstrate the development of language politics that enable indigenous education actions based on native languages. We discuss about studies of minority languages lexicon, such as Brazilian indigenous languages, the relevance of specialized lexicon research, which contributes to terminographic and lexicographic works. Taking into account the Ethnographic Terminology proposal (FARGETTI, 2019), the culinary field is focused among Juruna from the Xingu Indigenous Territory, Mato Grosso, and how its treatment in terminological vocabulary can contribute to intercultural bilingual education and registration of an important part of a Brazilian Tupi culture. For this, a specific fieldwork methodology is necessary, with a dialogue between sciences: that of the linguistic researcher and that of the indigenous specialist in an area of knowledge. Thus, a discussion of entry, with its subentries, prepared by Mondini (2014) is presented, in comparison with an entry in lexicographic work on other Brazilian indigenous language, which allows a contribution to Lexical Studies and its use in teaching.

Keywords: Indigenous language dictionary. Education. Etnographic Terminology.

\section{Introdução}

Das 180 línguas indígenas brasileiras que são estimadas como ainda hoje vivas (RODRIGUES, 2005; SEKI, 2000), poucas são contempladas com registros em boa quantidade e com documentação linguística aprofundada; muitas são consideradas obsolescentes ou ameaçadas de extinção, devido a sua situação de uso em declínio, morte de parte dos últimos falantes, adoção cada vez maior do português na maioria das interações e baixa transmissão para as gerações mais jovens ${ }^{1}$.

Assim, alguns dos diversos argumentos para a elaboração de dicionários e vocabulários de línguas indígenas podem passar por questões fundamentadas no direito à língua, na defesa da identidade linguística, étnica e territorial, na vontade de escrever e ler na língua materna quando da constituição de projetos de educação bilíngue intercultural. Documentos legais e projetos pedagógicos no âmbito das escolas indígenas mencionam o direito a materiais didáticos voltados à realidade social e cultural das comunidades de fala. Por exemplo, citamos o Projeto Político Pedagógico da Escola Kamadu (PPP, 2008), na aldeia juruna Tubatuba, no Parque Indígena Xingu (MT), que prevê materiais didáticos específicos, os quais podem ser dicionários, como nos mostra a Lexicografia Pedagógica.

\footnotetext{
${ }^{1}$ Apesar da existência de projetos pilotos promovidos pelo IPHAN, a proposta de inventário da diversidade linguística do Brasil não se efetivou, na verdade, a partir do decreto presidencial que a instituiu, No 7.387 de 9 de dezembro de 2010. Portanto, o número conhecido de línguas indígenas brasileiras é aproximado, em torno de 180 (ou menos, segundo alguns), apesar de o IBGE apresentar um número superior a esse em seu último censo.
} 
Este artigo pondera a possibilidade e a efetividade da produção de obras lexicográficas pedagógicas envolvendo línguas indígenas brasileiras. Paratanto, abordamos no iníciopontos sobrepolíticalinguística. Emseguida, fazemos um levantamento das iniciativas nacionais sobre a produção de material didático-pedagógico para comunidades indígenas, apontando que este material poderia ser constituído de dicionários e vocabulários. Para a elaboração de tais obras, discutimos aspectos da Lexicografia Pedagógica e apresentamos análise de verbetes propostos em duas obras lexicográficas distintas, pondo em pauta a relação entre Lexicografia e Terminologia, em especial em elementos de metodologia. É, portanto, nosso principal objetivo uma reflexão sobre as obras lexicográficas e terminográficas em línguas indígenas do Brasil e a realização de fato de obras voltadas ao ensino de tais línguas e sua revitalização.

\section{Sobre política linguística}

Ações afirmativas em respeito à diversidade linguística dos povos que habitam o território nacional têm sido propostas de forma ideal na legislação brasileira, há três décadas, possibilitando o início de uma política linguística em consideração às línguas minoritárias (em relação ao Português como língua oficial da nação). Os direitos assegurados pela Constituição atual (BRASIL, 1988) ao reconhecimento das línguas indígenas (Art. 231) e do ensino escolar destas (Art. $210 \$ 2^{\circ}$ ) foram reafirmados no programa de Diretrizes e Bases da Educação Nacional - LDB (BRASIL, 1996), que apontava: "O ensino fundamental regular será ministrado em língua portuguesa, assegurada às comunidades indígenas a utilização de suas línguas maternas e processos próprios de aprendizagem" (Art. $32 \S 3^{\circ}$ ); e: "(...) oferta de educação escolar bilíngüe e intercultural aos povos indígenas" (Art. 78).

Em 1991, o processo de legislação da educação escolar indígena rompeu com a política integracionista nacional, passando a competência de sua coordenação da Fundação Nacional do Índio (FUNAI) para o Ministério da Educação (BRASIL, 1991) e a administração às esferas estaduais e municipais. Desde então, diversos níveis de atuação governamental foram definidos, tais como: Núcleos de Educação Escolar Indígena (NEIs); Comissão Nacional de Educação Escolar Indígena; Conselhos Estaduais de Educação Escolar Indiggena; Coordenação Geral de Educação Escolar Indígena (CGEEI); Secretaria de Educação Continuada, Alfabetização, Diversidade (SECAD); Diretoria de Políticas de Educação do Campo, Indígena e para as Relações Étnico-Raciais. 
v. 11 (esp.)

$19-40$

ago.

2021

Em 1998, o Referencialcurricular nacional para as escolas indígenas (BRASIL, 1998) foi apresentado como proposta de suplementação à LDB, como instrumento auxiliar na formação de professores indígenas e na reflexão crítica no planejamento de cada currículo escolar, o que permitiu uma primeira observação aproximada da realidade plural das línguas indígenas ao anunciar a expectativa de que experiências pedagógicas surgissem de dentro das escolas indígenas.

No ano seguinte, foi apresentado o primeiro documento das Diretrizes curriculares nacionais da educação escolar indígena (BRASIL, 1999a), que criou a categoria Escola Indígena, observou condições limitantes da política integracionista e (posterior) ruralista do ensino escolar nas comunidades indígenas até então, e propôs a abrangência de cada unidade escolar para além das esferas municipais e estaduais até os territórios mesmos de cada povo indígena. Quando fixado legalmente (BRASIL, 1999b), o documento afirmou o funcionamento da escola nos territórios ocupados pela comunidade, o ensino na língua materna, a organização própria (Art. $2^{\circ}$ ) e a participação da comunidade no planejamento das atividades (Art.10).

Em 2004, o governo promulgou a Convenção n. 169 da OIT sobre Povos Indígenas e Tribais (BRASIL, 2004), documento de ação global que defendeu e reconheceu o direito dos povos interessados (indígenas ou tribais) em participar de modo colaborativo em programas de educação que lhes são destinados, de maneira a respeitar suas particularidades; e também determinou que os governos devam assegurar e transferir progressivamente a responsabilidade sobre esses programas e sobre a criação de novos dispositivos para as mãos de membros desses povos (Art. 27). Ainda determinou que seja possibilitada e defendida a alfabetização na língua indígena, tanto quanto na língua oficial da nação:

Sempre que for viável, dever-se-á ensinar às crianças dos povos interessados a ler e escrever na sua própria língua indígena ou na língua mais comumente falada no grupo a que pertençam. Quando isso não for viável, as autoridades competentes deverão efetuar consultas com esses povos com vistas a se adotar medidas que permitam atingir esse objetivo. (BRASIL, 2004, Art. 28)

Apenas em2009, surgiuapropostados TerritóriosEtnoeducacionais (TEEs) (BRASIL, 2009a), que se configuraram como unidades escolares autônomas, reconhecidas legalmente, e de direito em relação a cada particularidade territorial, linguística e cultural, com normas próprias e diretrizes curriculares específicas, que ofereçam ensino intercultural e bilíngue 
ou multilíngue (Art. $3^{\circ}$ ). Essas organizações passaram a ser estabelecidas na colaboração conjunta entre a comunidade e órgãos governamentais para o desenvolvimento de programas de formação de professores e de produção de materiais didáticos em respeito às particularidades culturais e educacionais de cada povo indígena.

Também em 2009, ocorreu a I Conferência Nacional de Educação Escolar Indígena (CONEEI) que, em caráter consultivo aos representantes dos povos indígenas, teve por objetivo promover o diálogo acerca do futuro das políticas de educação escolar indígena. Ao final, o Documento-síntese propôs a criação de um Sistema Próprio de Educação Escolar Indígena, nos TEEs (com ordenamento jurídico, de coordenação do MEC e com protagonismo indígena) e, também, de um Conselho Nacional dos Territórios Etnoeducacionais (com representação e indicação indígena); projetou autonomia e coletividade na construção dos projetos políticos-pedagógicos; prescreveu apoio do MEC a parcerias com institutos de ensino e pesquisa para a realização de estudos linguísticos das línguas indígenas, garantindo a devolutiva da pesquisa e a defesa do direito autoral dos povos; e projetou, ainda, a garantia da oficialização das línguas e a expectativa da modalidade de educação superior indígena, nos TEEs. A II CONEEI só ocorreu em 2016, também de caráter consultivo, e teve por objetivo discutir o regime de colaboração nos programas de educação escolar nos TEEIs.

O princípio básico de consideração com a diversidade étnico-racial só apareceu no texto da LDB 16 anos depois, em 2013 (BRASIL, 2013, Art. $1^{\circ}$ ), quando também foi instituído o dever do Estado de ofertar material didático-escolar em todas as etapas da educação básica (grifo nosso). Em 2014, o Plano Nacional de Educação PNE (BRASIL, 2014) determinou o regime de colaboração para a implementação dos TEEs, em consideração às "identidades e especificidades socioculturais e linguísticas de cada comunidade envolvida, assegurada a consulta prévia e informada a essa comunidade" (Art. $7^{\circ} \S 4$ ); determinou, ainda, que os entes federados estabeleçam estratégias que "assegurem a articulação das políticas educacionais com as demais políticas sociais, particularmente as culturais" (Art. $8^{\circ} \S 1^{\circ}$, inciso I) e que "considerem as necessidades específicas das populações do campo e das comunidades quilombolas, asseguradas a equidade educacional e a diversidade cultural" (Art. $8^{\circ}$ $\S 1^{0}$, inciso II). Atualizou, reafirmando "a oferta bilíngue na educação infantil e nos anos iniciais do ensino fundamental, em língua materna das comunidades indígenas e em língua portuguesa" (Estratégia 7.26). 


\section{v. 11 (esp.)}

19-40 ago. 2021

\section{Materiais didático-pedagógicos e os dicionários}

Ainda na esfera política idealizada, foram acordados direitos específicos para que "materiais didático-pedagógicos [sejam] produzidos de acordo com o contexto sócio-cultural de cada povo indígena" (BRASIL, 1999b, Art. $3^{\circ}$ § VI), sendo de competência da União e dos Estados "elaborar e publicar, sistematicamente, material didático específico e diferenciado, destinado às escolas indígenas" (BRASIL, 1999b, Art. $9^{\circ}$ § I-g; § II-f).

Em 2005, foi instituída por SECAD/MEC a Comissão Nacional de Apoio à Produção de Material Didático Indígena - CAPEMA (BRASIL, 2005) com o objetivo de promover o desenvolvimento do regime colaborativo na educação escolar indígena e criar uma rede de produção de material didático específico e de bibliotecas organizadas, para consolidar e fortalecer as línguas maternas. O processo de apresentação de obras e propostas de editoração ocorreriam a partir de chamadas públicas em editais.

A atenção foi reafirmada outras vezes, como no decreto dos TEEs (Art. 2 \& V - BRASIL, 2009a), e acrescidos de novas considerações:

Art. 10. A produção de material didático e para-didático para as escolas indígenas deverá apresentar conteúdos relacionados aos conhecimentos dos povos indígenas envolvidos, levando em consideração a sua tradição oral, e será publicado em versões bilíngües, multilíngües ou em línguas indígenas, incluindo as variações dialetais da língua portuguesa, conforme a necessidade das comunidades atendidas (BRASIL, 2009a).

Também, o PNE (BRASIL, 2014) apresentava como estratégias apoiar (5.5), consolidar (7.26) e desenvolver (7.27) o uso da língua materna pelas comunidades indígenas nas escolas presentes nas aldeias:

5.5) apoiar a alfabetização de crianças do campo, indígenas, quilombolas e de populações itinerantes, com a produção de materiais didáticos específicos, e desenvolver instrumentos de acompanhamento que considerem o uso da língua materna pelas comunidades indígenas e a identidade cultural das comunidades quilombolas; (...)

7.27) desenvolver currículos e propostas pedagógicas específicas para educação escolar para as escolas do campo e para as comunidades indígenas e quilombolas, incluindo os conteúdos culturais correspondentes às respectivas comunidades e considerando o fortalecimento das práticas socioculturais e da língua materna de cada comunidade indígena, produzindo e disponibilizando materiais didáticos específicos, inclusive para os (as) alunos (as) com deficiência; 
O Programa de Material Didático de 2010 e posteriormente o Programa Nacional do Livro e do Material Didático de 2017 PNLD (BRASIL, 2017) não mencionaram a especificidade da produção de materiais destinados às escolas indígenas ou quilombolas, mas afirmaram que o MEC poderia criar programas suplementares a públicos específicos, o que poderia ser uma remissão à CAPEMA acima referida (mas não há menção no texto).

A definição de material didático pode ser encontrada em um edital público onde há a chamada para a publicação desses materiais (Edital de Convocação MEC/SECAD n. 1, de 06/06/13): "Concebese como material didático e para-didático livros e outros suportes tecnológicos, como CDs, DVDs, e em linguagens que possam aproximar essa produção das tradições dos povos indígenas, como o uso da oralidade na transmissão dos conhecimentos". Apesar de o PNLD Dicionários (BRASIL, 2012) ter listado os dicionários monolíngues para falantes nativos como materiais didáticos para uso nas escolas públicas nacionais, ele não lista dicionários como materiais didáticos para as escolas indígenas.

O Programa Nacional de Tecnologia Educacional (ProInfo), apoiado na LDB e no PNLD, foi criado para publicar materiais didáticos em formatos de software ou hardware fechados, que auxiliassem o processo de ensino-aprendizagem nas escolas públicas. No Guia de Tecnologias Educacionais 2009, foi listado como tecnologia educacional o programa "Coleção Cineastas Indígenas" - um conjunto de 5 filmes sobre a cultura indígena, feitos pelos próprios indígenas -; e, no Guia de 2011/2012, foram listados, como tecnologias educacionais, além dessa coleção de filmes, os programas: "Territórios Etnoeducacionais" (os TEEs mencionados anteriormente), "Observatório da Educação Escolar Indígena", "Produção de Material Didático Indígena" e "PROLIND Programa de Formação Superior de Professores Indígenas". No Edital 25/2018 - SEB, houve a chamada para a apresentação de tecnologias educacionais para uso tanto nas escolas urbanas como rurais e indígenas; e essa tecnologia poderia ser compreendida como colaboradora na elaboração de um dicionário.

\section{A teorização do dicionário como material pedagógico}

A Lexicografia Pedagógica (LP), como ciência que estuda obras lexicográficas e propõe a sua elaboração com fins de aprendizagem 
v. 11 (esp.)

19-40 ago. 2021

e ensino escolar de línguas, em processo monolíngue (seja a língua estudada materna ou estrangeira) ou com mais de uma língua em relação, nos permite um arcabouço teórico de conceitos e métodos para a delimitação e a justificação do aspecto pedagógico dos dicionários. Todo dicionário é potencialmente didático (KRIEGER, 2007), pois é uma ferramenta fundamental no processo de ensino e aprendizagem de uma língua e pode auxiliar no processo de aprendizagem de outras disciplinas. Mas, nem todo dicionário é pedagógico. A atividade pedagógica objetiva o desenvolvimento do aprendizado em cada grau específico de aquisição do conhecimento por determinado aprendiz.

O interesse da LP é proporcionar ao usuário informações de qualidade para a obtenção de respostas para a realização de suas tarefas linguísticas (MOLINA GARCÍA, 2006), que podem suscitar questões em relação ao léxico, tais como: O que é isso? Como se escreve? Como se pronuncia? E, assim, os dicionários devem funcionar para a compreensão ou para a produção de textos, na língua materna do aprendiz ou em uma língua estrangeira aprendida. Como aponta Rangel (2011), nem toda obra lexicográfica de caráter escolar consegue atingir seus objetivos de utilização pelos alunos, uma vez que, segundo análise apontada pelo autor, há a necessidade do desenvolvimento da proficiência em consulta a dicionários, que devem ser adequados à faixa etária a que se destinam, o que não havia sido observado por propostas de minidicionários de língua portuguesa, incompreensíveis nas séries iniciais e desnecessários nas posteriores, por sua inadequação.

Hernández (1989) define critérios para a tipologia de dicionários didáticos, a partir do tipo dos usuários: 1) para usuários com conhecimento e domínio da língua, funcionam os dicionários gerais, usuais ou manuais (do tamanho das mãos); 2) a) para usuários em fase de aprendizagem de uma segunda língua funcionam os dicionários bilíngues ou os dicionários monolíngues para usuários estrangeiros; b) para usuários em fase de aprendizagem da língua materna funcionam dicionários escolares.

Os dicionários bilíngues podem ocorrer em uma única direção (L1 - L2) ou em duas direções (L1 - L2 e L2 - L1) e apresentar palavras "equivalentes" entre as línguas. Os monolíngues fornecem definições na mesma língua (WELKER, 2008). Os dicionários semibilíngues apresentam, entre a entrada e o equivalente, orações-modelo e definições que servem para esclarecer o significado da entrada, na mesma língua desta (SCHMITZ, 2001). 
Os dicionários escolares monolíngues perderiam na qualidade da oferta de informações ao se apoiarem na ideia de que todos os seus usuários são iguais, o que precisaria de uma motivação pedagógica por parte dos professores para que os aprendizes fizessem uso do material. Já os dicionários que contemplam duas línguas apresentam diálogo entre estas. Tanto em um caso quanto no outro, não se pode selecionar as entradas do dicionário com o pressuposto do que é ou não conhecido pelo usuário. Essa decisão deve ser tomada sob critérios do que é ou não pedagógico no momento certo para determinado usuário (CASTILLO CARBALLO; GARCÍA PLATERO, 2003), sendo que a organização do dicionário deve partir da definição do público-alvo de forma mais abrangente, para a consideração de suas necessidades e habilidades linguísticas (WELKER, 2008).

O dicionário é um livro, um conjunto de textos de gêneros diferentes: textos que antecedem ou que são posteriores à ordenação das entradas (macroestrutura) - como Prefácio, Introdução e Guia de usos; textos subliminares na ordem das palavras-entradas entre si (macroestrutura) - nomenclatura; e textos que definem os significados das entradas (microestrutura) - verbetes (WELKER, 2008).

No front matter da megaestrutura, deve-se instruir ao usuário qual a função do dicionário, se para a compreensão do texto ou se para a produção do texto na língua estrangeira; ainda, devese explicar as decisões tomadas para a seleção das entradas e sua organização, apresentar os critérios adotados, a finalidade da obra, seu usuário e seu tamanho. Na macroestrutura, deve-se apresentar a nomenclatura na língua de acesso, a ordenação das palavras em si, em ordem semasiológica ou por campos semânticos. Na microestrutura, devem-se apresentar as informações que permitam a compreensão do significado da palavra apresentada, se além da simples equivalência: entrada (separação por sílabas?); informação gramatical (necessária?); enumeração de diferentes acepções; definição; exemplos de uso e traduções destes (uso de negrito e aspas); uso de marcas (mudança de informações semânticas, linguísticas e culturais); sub-lemas. Pode-se fazer uso de estratégias didáticas que permitam com facilidade a visualização e a leitura intuitiva dos conteúdos: condensação de informações em sinais gráficos, na escrita, que permita a descondensação, na leitura; e definições com vocabulário controlado, que permita a visualização cíclica da obra como um todo (MOLINA GARCÍA, 2006). 
v. 11 (esp.)

19-40 ago. 2021

Essa estrutura apontada é comum às obras lexicográficas, inclusive às consideradas pedagógicas. Sobre suas origens e desenvolvimento, Vargas (2018) apresenta um histórico da Lexicografia Pedagógica, com seus primórdios relatados no final do século XIX, situa a área no Brasil, evidenciando a participação do Governo Federal em iniciativas e propostas para a escola no ensino básico, em especial com relação ao ensino de língua materna. Em trabalhos de Rangel (BRASIL, 2012; RANGEL, 2011; RANGEL; BAGNO, 2006), é tematizado o uso do dicionário em sala de aula em nosso país, em consonância com o PNLD, com a afirmação da necessidade de se explicitar a "proposta lexicográfica" dos elaboradores de obras voltadas ao ambiente escolar.

\section{Estudos do léxico de línguas indígenas e a educação escolar}

Obras lexicográficas monolíngues em língua indígena são raras, mas já começam a aparecer, como é o caso dos projetos de Dulce do Carmo Franceschini, entre os anos 2004 e 2008, que tiveram, como resultado, materiais didáticos, uma gramática pedagógica e um dicionário: todos monolíngues em sateré mawé, língua tupí, falada no Amazonas (obras de acesso restrito ao povo falante da língua). Mais frequentes são as obras lexicográficas bilíngues unidirecionais, com a língua indígena como acesso para o verbete na língua portuguesa (como o Dicionário Parkatêjê-Português ${ }^{2}$ - ARAÚJO, 2016). Poucas têm a língua portuguesa como acesso para a língua indígena (como o Dicionário de verbos Português-Yanomama3 - FERREIRA, 2011); outras poucas são bidirecionais (como o recém relançado Vocabulário Português-Nheengatu, Nheengatu-Português ${ }^{4}$ - STRADELLI,

\footnotetext{
${ }^{2}$ Obra fruto de trabalho da linguista Leopoldina Araújo, iniciado na década de 1970, e que pretende contribuir para a revitalização cultural da comunidade parkatêjê, que habita o município de Bom Jesus do Tocantins, no Pará.

3 Obra de objetivos incialmente pedagógicos, voltada aos alunos das escolas yanomama, um dos povos do grupo linguístico yanomami, que vive na fronteira entre Brasil e Venezuela, nos estados do Amazonas e de Roraima. Buscava-se, no início, o uso para o ensino de verbos do português para os yanomama e para outros povos do grupo yanomami, cujas línguas se assemelhariam. Esse objetivo se expandiu, colaborando com o ensino bilíngue, dada a ampla quantidade de exemplos em português que foram traduzidos para o yanomama, em busca de situações de uso cotidiano.
}

4 Ermanno Stradelli (1852-1926), conde italiano naturalizado brasileiro, era fluente em nheengatu, apesar de ter tido informante nativo da língua para realizar sua obra. Faleceu antes da primeira publicação desse vocabulário, ocorrida em 1929, na Revista do Instituto Histórico e Geográfico Brasileiro. Nheengatu é língua geral amazônica, antigamente muito usada por ribeirinhos, indígenas (como língua de contato) e moradores de cidades, como Belém do Pará. Hoje ainda é utilizada por ribeirinhos e indígenas da Amazônia. 
2014). Embora várias obras sejam construídas com a participação de professores indígenas, em oficinas e em trabalho direto de pesquisa, na verdade, a área de Estudos do Léxico tem pouco desenvolvimento nos cursos de formação, tanto de indígenas quanto de não-indígenas, e isso se reflete no trabalho dos pesquisadores. Atualmente, os trabalhos de documentação e organização de dados sobre as línguas indígenas ocorrem por pesquisas em grupos ou por indivíduos isolados e tais pesquisas são sediadas em núcleos descentralizados em universidades públicas ou particulares, instituições isoladas, empresas, institutos públicos, órgãos governamentais e não-governamentais, sejam nacionais ou internacionais. Nem sempre se tem acesso aos produtos de tais pesquisas, que, por vezes, não são comercializados, não são disponibilizados na internet e têm acesso restrito em repositórios e acervos.

Em catálogo de publicações entre os anos 2005 - 2008 (BRASIL, 2009), há a relação de textos de autoria de escritores indígenas, em suas línguas e no português, que foram publicados pela parceria SECAD/MEC/UFMG, para uso na escola: livros de alfabetização (na língua materna, na língua portuguesa e em matemática), oralidade, narrativas culturais, e sobre a escola; e um único glossário: Livro/glossário ilustrado bilíngüe nheẽgatú e werekena.

Outros textos de autoria indígena para uso como materiais didáticos foram publicados pela parceria SECAD/MEC entre os anos 2003 e 2008, escritos por professores indígenas, coletivamente, durante cursos para sua formação (magistério ou licenciatura intercultural) e são elencados por Figueiredo e Guimarães (2008). Esses textos contam sobre o Projeto Político Pedagógico na escola indígena, a tecelagem, as cantigas, a língua indígena, entre outros assuntos; o livro "Yasu yalery nheegatú" apresenta um vocabulário bilíngue (Neegatú-português) dos dias da semana e dos numerais. E, além dos textos, foram publicados CDs de música e DVDs de filmes. Apesar dos esforços, ainda temos um expressivo déficit de materiais didáticos para todas as etapas da educação básica intercultural indígena, principalmente para os anos finais do ensino fundamental e ensino médio, mesmo depois de doze anos da publicação referida anteriormente. No entanto, temos certeza de que os programas de formação superior de professores indígenas nas licenciaturas interculturais, apoiados pelo Ministério da Educação, hoje em andamento, serão capazes de acelerar e diversificar essa produção, ampliando-a para outras línguas indígenas. Diante de dados 
v. 11 (esp.)

$19-40$

ago.

2021

quantitativos, como aumento do número de escolas indígenas e de alunos nelas matriculados, observa-se que a necessidade de oferta de materiais didáticos específicos à educação escolar indígena é muito grande, e os trabalhos com o léxico demandam, em muitos casos, partir do ponto inicial.

\section{Em busca de uma metodologia}

Duran e Xatara (2007) apontam que a Lexicografia Pedagógica tem relação com três áreas, a saber: Linguística Computacional (computador como ferramenta na construção de obras lexicográficas), Linguística de Corpus (com o trabalho com grandes bancos de dados e sua seleção e classificação) e a Linguística Aplicada (com suas metodologias para a aprendizagem de línguas). Contudo, apesar da pertinência da relação apontada entre tais áreas, para a abordagem do léxico de línguas indígenas, não podemos contar com grandes bancos de dados, uma vez que elas não contam com tradição escrita (com existência de ainda ágrafas em nosso país), não contam com bancos de dados gravados e transcritos (ou apresentam pequenos bancos, em comparação com os das línguas com ampla produção literária) e, portanto, o trabalho com grandes corpora não se aplica a elas, requerendo uma abordagem de coleta de dados diferente e especializada. Assim, substituindo a Linguística de Corpus, para tais línguas faz-se necessária a interface com a Etnografia. Mas como isso pode ser feito em relação ao léxico? Fargetti (2019) sistematiza abordagem teórica e metodológica que subjaz a seu trabalho e ao de seu grupo de pesquisa: sua proposta da Terminologia Etnográfica.

Pela Terminologia Etnográfica (FARGETTI, 2019), não se partem de conceitos prévios para a obtenção dos termos e de suas definições. Parte-se de um desconhecimento, tão caro à Etnografia, realizando perguntas, tais como: "o que é isso?", "para que serve?", "como é feito?". Não são feitas perguntas, tais como "vocês têm isso?", "como tal coisa ocorre entre vocês?", pois tais perguntas não levam a respostas sobre um saber autêntico do povo, mas sim a um decalque da cultura do pesquisador. Algo como: "se o pesquisador diz que isso existe, acreditamos nele e por isso criamos e dizemos a palavra que ele quer ouvir". Afinal, uma língua viva permite a criação de léxico, que, no caso da pesquisa forçada, é apenas decalque que não fará parte do uso cotidiano. Se indagarmos outro falante, que não esteve presente 
na sessão de pesquisa, se conhece a palavra ouvida, ele dirá que não, que isso não existe, e que foi mesmo invenção de nosso informante. Esse tipo de situação não é incomum, infelizmente. E como conclusão, temos reafirmada a necessidade do efetivo conhecimento indígena como possibilidade de ciência e de considerar então que a ciência não seja algo singular e universal, mas sim delimitada na experiência de cada cultura. Se não consideramos isso, estaremos apenas colecionando os dados que queremos ouvir, os decalques falsos de nossa ciência, estaremos muito longe de compreender determinada cultura e a língua que a expressa.

Esses saberes científicos mencionados podem compor terminologias e estas podem e devem alimentar dicionários gerais de língua que cumpram os objetivos da comunidade de fala, em especial, o pedagógico. Chegar ao conhecimento desses saberes é algo complexo, pois toca as relações entre língua, cultura e pensamento, que são distintas em cada povo, e, além disso, essa busca de conhecimento é algo urgente, pois sabemos do perigo de perda cultural, com o falecimento das gerações mais velhas, detentoras de saber tradicional. Há, portanto, muito o que fazer, e a escola cumpre papel relevante nesse sentido e o estudo do léxico de línguas indígenas deve contar com um cuidadoso trabalho de campo, inclusive na escolha da variedade de língua a ser descrita. É grande preconceito, por falta de conhecimento, inclusive, pressupor que as línguas indígenas são idênticas umas às outras e que não possuam variedades.

Estas breves considerações sobre a abordagem teóricometodológica adotada pelo grupo LINBRA, que foi desenvolvida por Fargetti (2019) e tem norteado, por anos, trabalhos de seus alunos, está na base de nossas considerações, de nossa forma de pensar as análises seguintes.

\section{Uma análise comparativa entre duas obras}

O dicionário escolar da língua kaingang do Oeste paulista, organizado por D'Angelis e Gonçalves $(2018)^{5}$, trata de uma variedade da língua que se encontra obsolescente, com poucos falantes, e, por isso, a urgência de seu registro. Importante obra lexicográfica, contou com a participação de professores atuando na pesquisa e no registro, inclusive tratando de esparsos registros lexicais do passado. Foi iniciado, em 2013, um projeto de revitalização linguística, com a

${ }^{5}$ D'ANGELIS, W.R; GONÇALVES, S. A. (orgs.) Dicionário Kaingâk Paulista - a língua Kaingang no Oeste Paulista. Brasília: FUNAI, 2018. 
v. 11 (esp.)

19-40 ago.

2021

participação do grupo InDIOMAS (Unicamp), da ONG KAMURI e de regional da FUNAI. O dicionário é resultado desse esforço conjunto, cujas etapas são descritas por D'Angelis e Freitas (2019). Além de um prefácio, a obra tem explicações de como pode ser utilizada na escola, anotações sobre a grafia adotada e detalhes de pronúncia. O dicionário é bilíngue, bidirecional: kaingang-português e português-kaingang. A obra apresenta as referências de suas abonações, pequenos vocabulários anotados, por três estudiosos, na primeira metade do século XX, uma narrativa com tradução, créditos das imagens e as abreviaturas usadas. Os verbetes não apresentam transcrição fonética, mas têm indicação de classe de palavra, depois do equivalente, abonação com tradução. A seguir, um verbete dessa obra:

pentfu: farinha. (sub.). Ex: Pentfu pétót = farinha torrada.

(D'ANGELIS; GONÇALVES, 2018, p. 97)

Para estudos posteriores, poderíamos pensar em um desenvolvimento desse tipo de verbete, que incluísse informações culturais, distinguindo tipos de farinha, formas de preparo, entre outras características. Esse tipo de informação ${ }^{6}$ permite melhor compreensão do que foi registrado, possibilidade de comparação com itens lexicais de obras de outras línguas, com fins histórico-comparativos, revitalização linguística e cultural, entre outros fins. Esse desenvolvimento pode ser realizado através de pesquisa que leve em conta o saber especializado, no caso, sobre alimentação, em um tratamento terminológico que contribua com o registro lexicográfico. Sabemos que Lexicografia e Terminografia são distintas em seus pressupostos e metodologia, mas um estudo terminológico pode contribuir para verbetes mais adequados em um dicionário geral de língua, pensando-se em usuários de gerações futuras, por exemplo, que busquem conhecimento e sua revitalização na sociedade, o que parece ser um dos focos da obra sobre essa variedade de kaingang.

Um tratamento pela Terminologia Etnográfica (explicitada em FARGETTI, 2019) é adotado por Mondini (2014)7, em sua dissertação de

\footnotetext{
${ }^{6}$ Provavelmente, ainda possível de ser obtida, mesmo com a obsolescência da língua, uma vez que se trata de alimento largamente produzido por comunidades indígenas, que, seguramente, ainda é produzido pela comunidade de fala.

${ }^{7}$ MONDINI, J. N. Yudja Utaha: a culinária juruna no Parque Indígena Xingu - uma contribuição ao dicionário bilíngue juruna-português. 2014. 175 p. Dissertação (mestrado) - Universidade Estadual Paulista Júlio de Mesquita Filho, Faculdade de Ciências e Letras (Campus de Araraquara), 2014. Disponível em: http://hdl.handle.net/11449/127587.
} 
mestrado defendida na Unesp, quando aborda um início de vocabulário terminológico sobre alimentos preparados pelas mulheres juruna. Vejase abaixo entrada sobre farinha:

asa [a'sa] n. 1. farinha (nome geral) Informações enciclopédicas: alimento sólido, em farelos miúdos, e torrado produzido a partir de mandioca brava (amarga ou doce) ou macaxeira, ou a partir de grãos de milho. Alimento consumido diariamente, em todas as refeições, com peixe ou carne e mesmo quando já há beiju. Alimento que pode modificar um caldo de carne (de caça ou de peixe) em um pirão; mas, do qual não se pode dizer que se faz bebida fermentada (caxiri) ou não fermentada (mingau): por princípio, fazer farinha, fazer caxiri e fazer mingau são três processos diferentes. A oferta deste alimento dura o ano todo (a mandioca cresce o ano todo). A produção ocorre em grande quantidade, para que a farinha dure um mês ou mais (com exceção da farinha mole). Ver: etxukaha, mayaka, makaxi, makaxira, wãwaru. 2. farinha grossa Informações enciclopédicas: farinha produzida a partir de mandioca brava amarga, amolecida por pouco tempo na água; farinha em farelos com grânulos grandes. Esta farinha é elaborada com maior frequência em relação às demais, por isso é chamada pelo nome geral. Modo de preparo: deixar a mandioca brava amarga de molho na água, por 4 dias, até amolecerem; retirar do molho; extrair as partes duras (cascas, pontas e fibras, que são reservadas ao sol para depois serem aproveitadas em outras receitas); despedaçar a polpa com as mãos; espremer no tipiti (o líquido que vaza não retorna à receita, pois contém veneno); peneirar (peneira de furos largos) para fragmentar e extrair os grumos (que são reservados com as demais partes duras); umedecer com um pouco de água; torrar no tacho quente, sobre o fogo; torrar bastante; mexer o tempo todo para torrar tudo por igual (foto 21). O consumo pode durar um mês. A oferta deste alimento dura o ano todo. Ver: asaka, iya heyahã, mayaka; cont. ami, akïrïhã. 
v. 11 (esp.)

19-40

ago.

2021

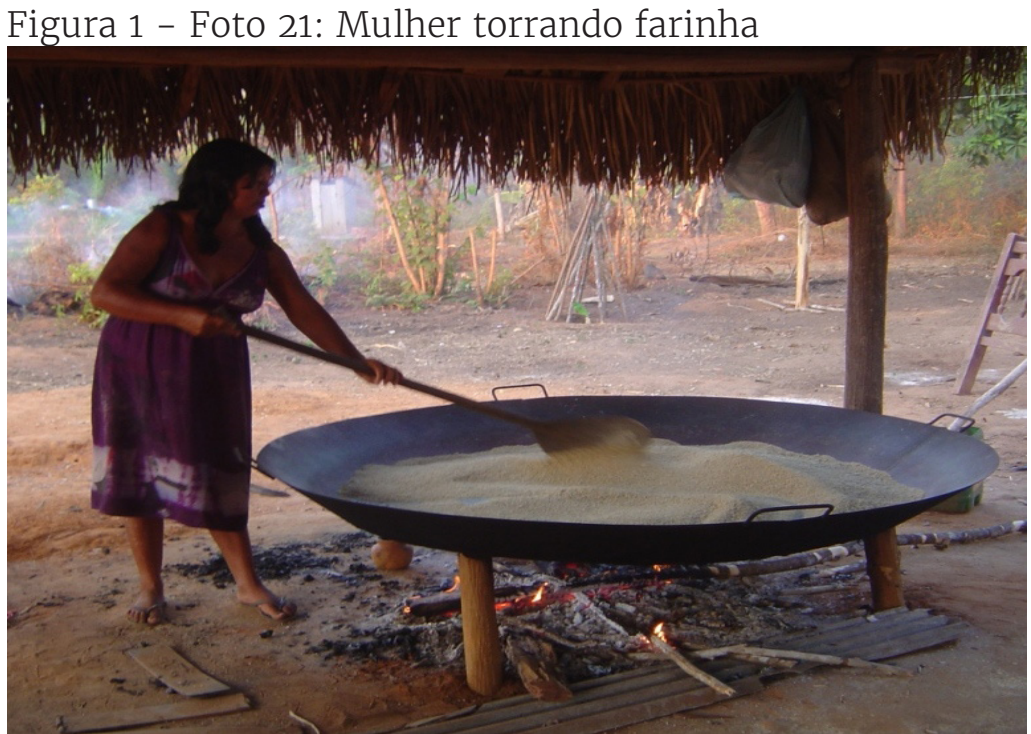

Fonte: Mondini (2014, p. 106).

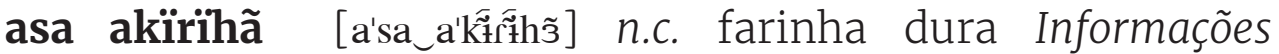
enciclopédicas: farinha produzida a partir dos cortes (partes duras) da mandioca brava (amarga ou doce), cascas, pontas, fibras e grumos que foram separados de outras receitas, secos ao sol; farinha em farelos miúdos e grânulos duros. Modo de preparo: deixar as partes duras secarem ao sol por 4 ou 5 dias; pilar tudo junto; umedecer com um pouco de água; torrar no tacho quente, sobre o fogo; mexer o tempo todo para torrar tudo por igual. O consumo pode durar um mês. A oferta deste alimento dura o ano todo. Ver: mayaka, wãwaru; cont. akïrïhã.

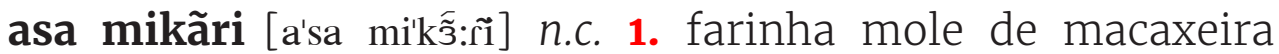
Informações enciclopédicas: farinha produzida a partir de macaxeira; farinha em goma com grânulos macios. Modo de preparo: deixar a macaxeira de molho na água por 3 dias, até amolecer; descascar e retirar as partes duras (suas sobras não são reaproveitadas); espremer no tipiti, para retirar o excesso de água; peneirar (na peneira de furos largos); torrar no tacho quente, sobre o fogo; mexer o tempo todo; não deixar torrar por completo; retirar ainda mole. O consumo é imediato. A oferta deste alimento dura o ano todo. Ver: makaxira. 2. farinha mole de massa de mandioca brava doce pubada. Informações enciclopédicas: farinha produzida a partir da massa de mandioca brava doce amolecida por longo tempo em água (pubada); farinha 
em goma com grânulos macios (fotos 22, 23). Também é chamada de "a farinha dos mortos". Modo de preparo: peneirar a massa de mandioca brava doce pubada; torrar no tacho quente, sobre o fogo; mexer o tempo todo; não deixar torrar por completo; retirar do fogo ainda mole. O consumo é imediato. A oferta deste alimento dura o ano todo. Ver: wãwaru; cont. lawabeha.

Figura 2 - Foto 22: Menino comendo farinha mole

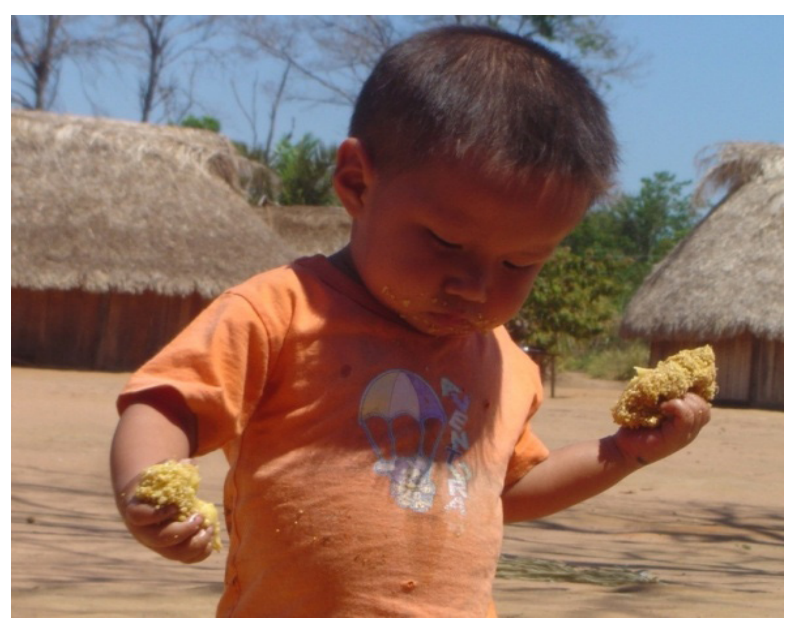

Fonte: Mondini (2014, p. 107).
Figura 3 - Foto 23: asa mikãri (ampliação da foto 22 )

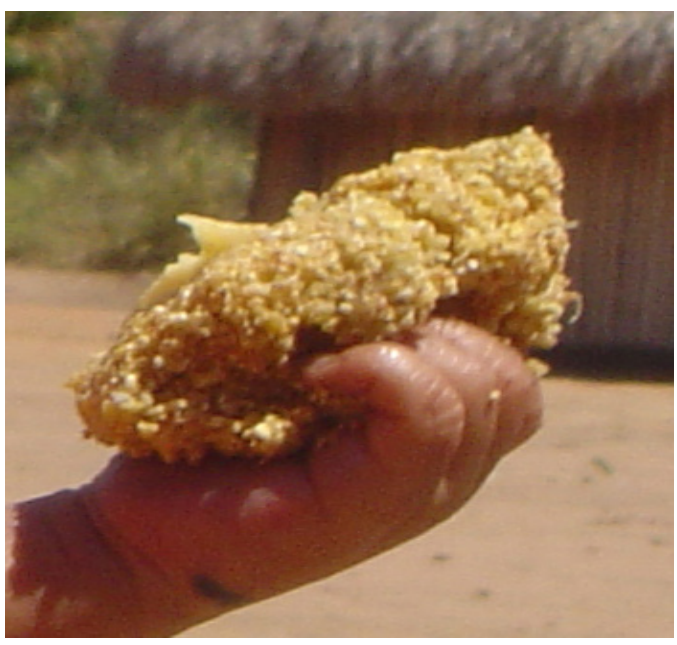

Fonte: Mondini (2014, p. 107).

asa ikutakuta [a'sa iku'tákúta] n.c. farinha fina Informações enciclopédicas: farinha produzida a partir de massa de mandioca brava amarga amolecida por longo tempo em água (pubada); farinha em farelos com grânulos bem finos. Modo de preparo: peneirar a massa de mandioca brava amarga pubada e torrar no tacho quente, sobre o fogo; mexer o tempo todo, para torrar tudo por igual. $\mathrm{O}$ consumo desta farinha pode durar um mês. A oferta deste alimento dura o ano todo. Ver: mayaka; cont. lawabeha.

makaxi asa [maka'jí a'sa] n.c. farinha de milho Informações enciclopédicas: nome geral para três diferentes farinhas produzidas a partir do milho. Os grãos de milho podem ser verdes ou secos, processados em três formas diferentes: amido doce, amido azedo e grão torrado na espiga. Ver: makaxi; hip. maipudju, punana, txaberi.

(MONDINI, 2014, p. 105-107) 
v. 11 (esp.)

$19-40$

ago.

2021

Notam-se no verbete: lema seguindo ortografia da língua; transcrição fonética, com marcação inclusive de traços suprassegmentais; classe de palavra; equivalente; informações enciclopédicas, descrevendo o tipo específico de farinha (no caso, seriam cinco tipos); modo de preparo do alimento, com descrições de sua matéria prima, de seu formato, de sua consistência; dados sobre consumo e oferta do alimento; remissivas e imagens ilustrativas (fotos feitas pela autora, em trabalho de campo); tratamento equiparado para os sub-lemas. Para se chegar a este detalhamento, Mondini realizou pesquisa etnográfica junto às mulheres da comunidade juruna, em observação participativa, como proposta pela Etnografia, buscando chegar aos termos específicos da culinária. Este trabalho da autora contribui para o conhecimento terminológico sobre alimentação indígena e aponta caminhos para outros pesquisadores. Parte do princípio que os saberes sobre os alimentos constituem uma área de conhecimento próprio das mulheres juruna e esse conhecimento pode ser tido como uma ciência. Seguindo Fargetti (2019), pensamos que não podemos ter a universalidade da Ciência, mas ciências distintas, de acordo com saberes específicos de povos diferentes. O universal se dá na diversidade, que deve ser respeitada, em suas manifestações, e compreendida, nos estudos envolvendo léxico, inclusive.

\section{Considerações finais}

Como apresentamos neste texto, a política linguística brasileira em relação a diversidades linguísticas e, em especial, em respeito a línguas indígenas tem se desenvolvido. Não há impedimentos legais hoje para a manifestação, o uso intensivo, o registro (inclusive em publicações) das línguas indígenas. As escolas indígenas em seus Territórios Etnoeducacionais são previstas, legais e efetivadas: a alfabetização na língua materna pode ocorrer. Contudo, apenas alfabetização não basta e apenas leis não são suficientes para alterar séculos de discriminação, preconceito, colonialismo e perda linguística e de identidade. São necessárias ações de promoção e valorização da diversidade linguística e cultural, as quais incluem aportes financeiros para a realização de pesquisas de base, para a formação continuada de professores indígenas e para a elaboração de materiais didáticos apropriados às realidades diferentes de povos brasileiros, fortalecendo iniciativas já existentes dos centros de pesquisa e de formação em todo país. 
A produção de dicionários de línguas indígenas é requerida para a salvaguarda dessas línguas e dos conhecimentos culturais. Para chegar a essas obras, são necessários anos de estudo, pesquisa, documentação e diálogo entre a academia e os falantes das línguas, que podem deixar de ser minorizadas e passar a ter seus direitos reconhecidos. Abordagens teórico-metodológicas, como a da Terminologia Etnográfica, aqui referida, podem contribuir muito para o desenvolvimento de pesquisas sobre léxico de especialidade, que componha dicionários gerais de língua mais abrangentes e apropriados para a documentação, o ensino e a revitalização linguística. O movimento pedagógico ocorre na projeção de que essas obras possam auxiliar o ensino-aprendizado da língua indígena nas escolas e auxiliar o desenvolvimento da literatura indígena escrita. Assim, podemos considerar o contexto sócio-político do surgimento de uma Lexicografia Pedagógica de Línguas Indígenas, pois ela se torna possível, viável, necessária e urgente.

Agradecimentos: Agradecemos à CAPES, por bolsa de estudos de doutorado e por auxílio ao trabalho de campo, através de financiamento em projeto de pesquisa; ao Programa de Pós-Graduação em Linguística e Língua Portuguesa da Unesp de Araraquara, por auxílio em trabalho de campo; a Odair Luiz Nadin, pela leitura de versão anterior deste texto e por suas sugestões; aos pareceristas da Revista Entrepalavras, por seus comentários, que colaboraram com a versão final do texto; ao povo juruna, pela acolhida e pela participação ativa nos projetos do Grupo LINBRA.

\section{Referências}

ARAÚJO, L. Dicionário Parkatêjê-Português. Belém: Edição da Autora, 2016.

BRASIL. Decreto n. 9.099, de 18 de julho de 2017. Dispõe sobre o Programa Nacional do Livro e do Material Didático. Diário Oficial da União. Brasilia, 19 de julho de 2017.

BRASIL. Lei n. 13.005, de 25 de junho de 2014. Aprova o Plano Nacional de Educação - PNE e dá outras providências. Diário Oficial da União. Edição Extra. Brasília, 26 de junho de 2014.

BRASIL. Lei n. 12.796, de 4 de abril de 2013. Altera a Lei no 9.394, de 20 de dezembro de 1996, que estabelece as diretrizes e bases da educação nacional, para dispor sobre a formação dos profissionais da educação e dar outras providências. Diário Oficial da União. Brasília, p. 1, 5 de abril de 2013. 
v. 11 (esp.)

19-40 ago. 2021

BRASIL. Com direito à palavra: dicionários em sala de aula / [elaboração Egon Rangel]. - Brasília: Ministério da Educação, Secretaria de Educação Básica, 2012 .

BRASIL. Indígena na Educação Básica. Brasília: MEC, 2012.

BRASIL. Decreto n. 6.861, de 27 de maio de 2009. Dispõe sobre a Educação Escolar Indígena, define sua organização em territórios etnoeducacionais, e dá outras providências. Diário Oficial da União, Brasília, p. 23, 28 de maio 2009a.

BRASIL. Catálogo de Publicações: projeto 8273 SECAD-MEC/FALE-UFMG - publicação de obras de autoria indígena. Belo Horizonte: UFMG, 2009b. Disponível em < http://www.letras.ufmg.br/indigena/>. Acesso em: $1^{\mathrm{O}}$ de jun. de 2020.

BRASIL. Portaria n. 13, de 21 de julho de 2005. Institui, no âmbito da Secretaria de Educação Continuada, Alfabetização e Diversidade - SECAD, a Comissão Nacional de Apoio à Produção de Material Didático Indígena - CAPEMA. Diário Oficial da União. Brasília, 25 de julho de 2005.

BRASIL. Convenção n. 169 da OIT (Organização Internacional do Trabalho) Sobre povos indígenas e tribais e resolução referente à ação da OIT sobre povos indígenas e tribais. Brasília: OIT, 2004.

BRASIL. Conselho Nacional de Educação. Parecer n. 14 de 14 de setembro de 1999. Diretrizes curriculares nacionais da educação escolar indígena. Diário Oficial Da União, Brasília, 14 set. 1999a.

BRASIL. Resolução n. 003/99. Fixa diretrizes nacionais para o funcionamento das escolas indígenas e dá outras providências. Diário Oficial da União. Brasília, p. 58, 10 nov. 1999 b.

BRASIL. Referencial Curricular Nacional para as Escolas Indígenas. Brasília: MEC, 1998.

BRASIL. Lei de Diretrizes e Bases da Educação Nacional. Brasília: MEC, 1996.

BRASIL. Decreto n. 26 de 04 de fevereiro de 1991. Dispõe sobre a educação indígena no Brasil. Diário Oficial da União, Brasília, p. 2487, 04 fev.1991.

BRASIL. Constituição da República Federativa do Brasil. Brasília: Presidência da República, 1988.

CASTILLO CARBALLO, M. A.; GARCÍA PLATERO, J. M. La lexicografía didáctica. In: MEDINA GUERRA, A. M. (coord.). Lexicografía Española. Barcelona: Ariel, 2003, pp. 333-351.

D'ANGELIS, W.R.; FREITAS, M.G.M. Dicionário Kaingâk Paulista: recolha lexical de um dialeto obsolescente. In: D'ANGELIS, W.R.(org.) Revitalização de línguas indígenas - $\mathrm{O}$ que é? Como fazemos. Campinas: Editora Curt Nimuendajú, 2019, p.111-132

D'ANGELIS, W.R; GONÇALVES, S. A. (orgs.) Dicionário Kaingâk Paulista - a língua Kaingang no Oeste Paulista. Brasilia: FUNAI, 2018. 
DURAN, M. S.; XATARA, C. M. Lexicografia Pedagógica: atores e interfaces. D.E.L.T.A., 23:2, 2007, p. 203-222.

FARGETTI, C. M. Para uma Terminologia Etnográfica. In: ZAVAGLIA, C.; NADIN, O. L. (orgs.) De histórias, palavras e dicionários : estudos em homenagem à Clotilde de Almeida Azevedo Murakawa. Campinas, SP : Mercado de Letras, 2019 (Série Estudos do Léxico), p. 137-170.

FERREIRA, H. P. (org.) Dicionário de verbos: português-yanomama. São Paulo: ISA, 2011.

FIGUEIREDO, N.; GUIMARÃES, S.G. (orgs.) Materiais didáticos e para-didáticos em línguas indígenas. Brasília: CAPEMA/SECAD/MEC, 2008. Disponível em $<$ http://portal.mec.gov.br/secad/arquivos/pdf/indigena/didatico_indigena. pdf $>$. Acesso em: $1^{0}$ de jun. de 2020.

HERNÁNDEZ, Humberto. Los diccionarios de orientación escolar: contribuición al estudio de la lexicografía monolíngüe española. Tubigen: Niemeyer, 1989.

KRIEGER, M. G. O dicionário de língua como potencial instrumento didático. In: ISQUERDO, A. N.; ALVES, I. M. (orgs.). As Ciências do Léxico: lexicologia, lexicografia, terminologia. Campo Grande: Ed. UFMS; São Paulo: Humanitas, 2007, p. 295-309.

MOLINA GARCÍA, D. Fraseología bilingüe: un enfoque lexicográficopedagógico. Granada: Comares, 2006.

MONDINI, J. N. Yudja Utaha: a culinária juruna no Parque Indígena Xingu - uma contribuição ao dicionário bilíngue juruna-português. 2014. 175 p. Dissertação (mestrado) - Universidade Estadual Paulista Júlio de Mesquita Filho, Faculdade de Ciências e Letras (Campus de Araraquara), 2014. Disponível em < http://hdl.handle.net/11449/127587>. Acesso em: $1^{0}$ de jun. de 2020.

PPP - Projeto Político Pedagógico da Escola Estadual Indígena de Educação Básica Central KAMADU - Povo Yudja, Aldeia Tuba Tuba, 24 de novembro de 2008 (assessoria do Instituto Socioambiental/ISA) (não publicado).

RANGEL, E. O. Dicionários escolares e políticas públicas em educação: a relevância da "proposta lexicográfica". In: CARVALHO, O.L.S.; BAGNO, $M$. (orgs.) Dicionários escolares - políticas, formas \& usos. São Paulo: Parábola Editorial, 2011, p.37-60.

RANGEL, E. O.; BAGNO, M. Dicionários em sala de aula. Brasília: MEC, Secretaria de Educação Básica, 2006.

RODRIGUES, A. Sobre as línguas indígenas e sua pesquisa no Brasil. In: Ciência e Cultura, vol. 57, n. 2. São Paulo: Sociedade Brasileira para o Progresso da Ciência, 2005, p. 35-38.

SCHMITZ, J. R. A problemática dos dicionários bilíngues. In: OLIVEIRA, A.M.P.P; ISQUERDO, A.N. (Orgs.). As Ciências do Léxico: lexicologia, lexicografia, Terminologia. (2 ${ }^{\mathrm{a}}$ ed.). Campo Grande: UFMS, 2001, p. 161-170.

SEKI, L. Línguas indígenas do Brasil no limiar do século XXI. In: Impulso, vol. 12, n. 27. SP: Universidade Metodista de Piracicaba, 2000. 
v. 11 (esp.)

$19-40$

ago.

2021

STRADELLI, E. Vocabulário Português-Nheengatu/ Nheengatu-Português. Cotia: Ateliê Editorial, 2014 [1929].

VARGAS, M. D. Lexicografia Pedagógica: história e panorama em contexto brasileiro. In: DOMÍNIOS DE LINGU@GEM, v. 12, 2018, p. 1935-1949.

WELKER, H. A. Lexicografia Pedagógica: definições, história, peculiaridades. In: XATARA, C.; BEVILACQUA, C.; HUMBLÉ, P. (orgs.) Lexicografia Pedagógica: Pesquisas e Perspectivas. Florianópolis: UFSC, 2008, p. 9-45. 